\title{
The Effect of Collaborative Writing on EFL Learners Writing Ability at Elementary Level
}

\author{
Masoumeh Shiri Aminloo \\ Department of English Language, Damavand Branch, Islamic Azad University, Damavand, Iran
}

\begin{abstract}
The present study examines the effect of group work and collaborative writing on EFL learners' writing ability at elementary level. Convenience sampling is used in this research. 64 learners in two groups (treatment \& control) participated in the study. The Learners in treatment group wrote their writings collaboratively while the other group wrote them individually. The writing samples were rated based on the TOEFL iBT task 2 writing scoring rubric (ETS, 2006). The results showed that both the treatment group and the control group improved significantly from the beginning to the end of the instruction as assessed through the use of two paired samples t tests (Treatment Group $t(30)=-26.42, p=.000$; Control Group $t(32)=-15.70, p$ $=.000)$. However, the two groups showed a significant difference in their posttest $(t(62)=2.64, p=.01)$.
\end{abstract}

Index Terms - cooperative learning, writing, cognitive skills

\section{INTRODUCTION}

\section{Cooperative learning}

Cooperative learning can be defined as a variety of concepts and techniques for enhancing the value of student student interaction (Tan, 1999).

Keyser (2000) introduces cooperative learning as one variety of active learning which structures students into groups with defined roles for each student and a task for the group to accomplish.

The purpose of cooperative learning is to enhance cognitive and social skills via a set of known techniques. Interdependence, accountability, group formation, social skills, and structure are all built the sequence and communicated to the students in multiple ways.

Research on merits and demerits of cooperative learning

Numerous studies indicate that compared to competitive or individualistic learning experiences, cooperative learning is more effective in promoting intrinsic motivation and task achievement, generating higher order thinking skills, improving attitudes toward the subject, developing academic peer norms, heightening self - esteem, increasing time on task, creating caring and altruistic relationships, and lowering anxiety and prejudice. (Ghaith \& Yaghi, 1998)

By thinking and writing in a group, we are likelier to develop our ideas more fully and more creatively. Peter Elbow explains, "Two heads are better than one because two heads can make conflicting material integrate better than one head can. It's why brainstorming works.

However, sometimes conflict arises from group members' failure to meet schedules, or to complete their share of the work. Personality conflicts, although less common, are also problematic. Brumberger (1999) mentions that collaborative writing does not seem to consistently result in a better product, nor does it necessarily result in visibly improved writing skills.

\section{Heterogeneous grouping}

According to cooperative - learning research outside the L2 field, structured forms of teacher - assigned heterogeneous grouping can enhance relations among classmates, promote learner to learner tutoring, increase tolerance, decrease prejudice, and promote cross cultural understanding (Kagan,1985) although such grouping involves increased thought, effort, and energy on the part of the teacher. Heterogeneous grouping can be done on the basis of language proficiency, language background, ethnicity, gender, or other factors. Similarly, Brumberger (1999) states that learners are grouped into heterogeneous groups in order to enhance social skills and other non - cognitive outcomes such as inter - ethnic relationships, self -esteem, liking of school and so forth.

It is true that less profitable interaction is found within peer groups, sometimes because of the participant's lack of trust in the accuracy, sincerity, and specificity of the comments of their peers (Zhang 1995). Certainly the often promoted affective advantages of peer response over teacher response (less threatening, less authoritarian, friendlier, more supportive, and so on) have not been immediately recognized by students, nor indeed supported by research. In several studies, peer feedback has been judged by the participants as less helpful than the teacher's feedback, and in one case even less useful than a native speaker friend or grammar book (Leki, 1991).

\section{Good groups and bad groups}

In a good group, your idea will be received with the understanding that it's necessarily preliminary and tentative, and you won't have to worry about being punished for it. In a bad group, you'll quickly realize that your major task is to turn your associates into a good group. 
A good group is accepting and supportive. In this group good ideas are rewarded. Members look forward to participating because their ideas are respected. Everybody pitches in, and everybody wins.

"Group IQ" is higher in a good group. Group IQ is a product not only of the sum of the group's intelligence but the sum of the group's social skills. Intelligence without social skills - or social skills without intelligence - handicap a group severely (Goleman, 1996).

Brumberger (1999) states that comments often focused on group members are: "hard to work with" , "control freak" , and "unreliable" were typical comments in groups that had problems; and" helpful" , "dependable" , "enthusiastic" , and "good attitude" were common in more successful groups.

Good group members constantly remember that their own personal interest is interdependent with the interests of other members: "One for all" not "All for "one".

High-achieving students VS. Low-achieving students

There is more conflicting evidence in the literature regarding whether cooperative learning is equally beneficial to students at all levels of prior achievement. Some maintain that High-achievers would benefit most from cooperative learning because they provide frequent elaborated explanations. Johnson (1985) asserts that the learning of high achieving students usually benefited and never suffered when they were grouped with lower - achieving peers.

However, Ghaith (2001) argued against the use of cooperative learning with gifted students based on the assumption that the high achievers could be held back by having to ensure the learning of their low - achieving team mates. Consequently, the researcher proposes that cooperative learning could be beneficial for the low -achieving learners who make learning gains at the expense of the high achievers.

In a different investigation by $\mathrm{Li}$ and Adamson (1992) gifted secondary students tended to like individualistic learning (and sometimes competitive learning).

However, Johnson (1985) asserts that the learning of high - achieving students usually benefited and never suffered when they were grouped with lower - achieving peers.

Application of social constructivism to collaborative learning in the $\mathbf{L} 2$ classroom

The purpose of cooperative learning is to enhance cognitive and social skills via a set of known techniques. Interdependence, accountability, group formation, social skills, and structure are all built the sequence and communicated to the students in multiple ways.

Lev Vygotsky, a Russian psychologist, contributed significantly to social constructivist epistemology. Like Dewey, Vygotsky recognized that ideas have social origins; they are constructed through communication with others. He also introduced the concept of the Zone of Proximal Development (ZPD), that is, the realm of potential learning that each learner could reach within a given developmental span under optimal circumstances and with the best possible support from the teacher and others in the environment (The modern language journal, 1997).

For Vygotsky (1986), the teacher acts as a facilitator or guide and the provider of assistance. Teachers perform a great service to students by providing any and all forms of assistance that might help students develop their language and cultural skills.

Therefore, the L2 learning process is situated in a particular social context. It involves becoming part of the culture of the learning community.

\section{Factors that affect cooperation}

Jacobs (1988) believes many factors can affect cooperation; They include the grading system used, students' previous educational experiences, types of intrinsic and extrinsic motivation among students' friendships between students, and social norms.

He also maintains that another step in the preparation of the class for cooperative learning was to talk about some of the skills necessary to productive group functioning. These include making sure everyone participate; paying attention when others speak; pointing out good points in compositions, not only mistakes; and criticizing the draft, but not the person who has written it.

\section{Process Writing}

According to Rao (2007), Instead of focusing on teaching students how to produce correct writing products, university EFL teachers should adopt a process - based approach, providing their students with opportunities to interact with each other. This is particularly important when learners lack ideas and information for a writing task. Since peer help and cooperation are of paramount importance in the use of brainstorming strategy, strategy training should emphasize team work.

Spacks (1998) suggest a process - centered course around text - based or data - based tasks in which written language acts as a medium of learning something else. Students should learn general inquiry strategies, rhetorical principles, tasks that can transfer to other course work.

\section{Responding to writing}

Writing is a complex and multifaceted activity. When we assess writing, we engage in another complex and multifaceted activity. Different techniques can be used in correction process. We can correct errors; code errors; locate errors; indicate the number of errors. Holistic scoring is used in this research.

Collaborative writing

Ferris (1994) believes that"inadequate content", "poor organization", and "stylistic inappropriateness" are weaknesses 
of student writers. Therefore it is assumed that the students can improve their writing by working in groups.

In this research, it is believed that confident student writers can give confidence to those who lack self confidence. In this regard Zimmet (2000) expresses that:

Collaborative work and small group discussion seem to give even the shyest students enough security to participate more frequently.

She also shows how collaboration helped take their thinking further than it might otherwise have gone.

Kirkland and Saunders (1991) maintain that the activities in collaborative writing can begin orally and progress to collaborative written exercises in which students supply topic sentences and main idea sentences. Such activities typically begin with concrete material and move to more abstract content. They also state that as we work on super ordination, modeling or demonstrating our own thinking process aloud for students can be very helpful in clarifying our expectations in terms of cognitive and meta-cognitive operations.

\section{Methodology}

\section{Participants}

38 female and 26 male EFL learners of differing majors studying at the University of Tehran, Kish International Campus took part in the present study. The treatment group consisted of 31 students (17 female and 14 male), while the control group consisted of 33 students ( 21 female and 12 male) students. They took the writing course as part of an English package offered to every new student at that university. Their age ranged from 20 to 37, with an age mean of 26.

\section{Materials}

The main material used was a number of TOEFL iBT writing prompts chosen from the ETS TOEFL Writing Prompts Official Booklet available at ETS website.

\section{Procedure}

All new students, before being admitted, have to take an English proficiency test designed by the English department at the Faculty of Foreign Languages and Literatures, University of Tehran, Iran. This test is generally known as U-Test or UTEPT. It consists 100 items. The first 30 items measure learners' knowledge of grammar and written expressions. The second 30 items measure vocabulary through different item formats including multiple choice items and Cloze tests. Finally, the last 40 items are devoted to assessing learners' reading comprehension. There is no listening, speaking or writing section in this test. However, after this test, each candidate is interviewed with a two person team of teachers who have been teaching at that university for a long enough time to be quite familiar with the requirements and objectives of the English program there.

Based on the results of the U-test and the interview done, students are either exempted or grouped into 3 levels. Those scoring below 25 are assigned to group $\mathrm{C}$, which roughly equals the basic level. Those scoring between 25 and 40 are assigned to group B, which is roughly equivalent to the elementary level. Those scoring between 41 and 75 are assigned to group A, which matches the intermediate level in language institutes. Finally, those scoring above 75 are regarded as advanced learners of English and are exempted from the program. Only groups A and B receive writing instruction as part of the package offered to them. Those in group B are taught 'paragraph writing' only, while those in group A received instruction on essay writing as well. The participants in this study were those taking writing instruction as part of their English program in group B. As such, by using the term 'elementary' in the title of the study, the researcher means those assigned to group B through the procedure described above.

Convenience sampling was used in the present study. In other words, the treatment and control groups were intact groups. There were 3 writing classes available, and 2 were randomly chosen first. Then, the two classes were randomly assigned to control and treatment groups.

It was a 2 unit writing course held in the second semester. During the semester, 12 sessions were actually held, one of which was devoted to the final exam. In the first session, a topic was given to both groups, and they were given 30 minutes to write a paragraph of at least 120 words. This was taken as their pretest. During the first 4 sessions, the basics of paragraph writing were taught. A process approach to writing was followed. Students were taught to go through different stages of writing starting with brainstorming and outline making for the given topic. Then, they were required to pre-write observing the rules taught about including a topic sentence, supporting sentences, and conclusion. Next, they had to revise it. Finally, they were taught how to edit their writing samples for spelling, punctuation, and grammatical mistakes. In the rest of the semester, one topic was chosen for each session and students were required to go through all these stages under the supervision of their teacher during the class time.

Up to this point everything was the same for both groups. However, from the 6th session, students in the treatment group were divided into groups of three and were required to go through the different stages of writing together. They were required to do the brainstorming together. Read each other's outlines and first drafts and give feedback to each other. After writing the revised version, each member of the group had to read his/her friends' revised version and help them edit their writings. The students in the control group, however, had to go through these stages individually. At the end of each session, students' writing in both groups were collected and commented on by the teacher. Learners' final exam was taken as their posttest. The writing samples were rated based on the TOEFL iBT task 2 writing scoring rubric (ETS, 2006). 
In order to avoid the effects of handwriting on the raters, all the gathered samples were typed by the researcher. The researcher was cautious to type them as they were actually written by the participants, i.e., all misspellings, wrong punctuations, and other types of mistakes were typed exactly as they had appeared in the scripts.

The samples were then given to two experienced university faculty members to be rated. Before rating the samples, a meeting was arranged with both raters and the procedure and the type of scoring guide were explained to them. However, they were not clued in on the purpose of the study.

In case the scores given by the two raters differed by two band scores, a third rater was used and the average between the third rater and the one closer to his score was taken as the final score. In case of the rest of samples, the average between the two raters was taken into data analysis.

\section{DATAANALYSIS}

The null hypothesis was tested through two different procedures. In one method, learners' pretest and posttest were compared with each other, and then their post tests were compared through the use of independent samples t test. Also, each group's pretest and post test were compared with each other to see if the two groups had improved over time.

\section{Rater Reliability}

The inter-rater and intra-rater reliability indices were calculated through the use of Pearson product-moment correlation. An estimate of .93 was obtained in the case of inter-rater reliability. Also after having raters re-rate $25 \%$ of the randomly selected samples; the researcher calculated the correlation coefficient between the scores given by the raters in their first and second attempts. The obtained correlation coefficient for rater 1 was .96 and for rater 2 was .89.

When the raters are trained to judge based on a scale rubric, the consensus estimates including the percent exact agreement and adjacent agreement between raters could act as the best measures of agreement. The percent exact agreement obtained was $83 \%$ and the adjacent agreement index was $94 \%$.

\section{Examining the Null Hypotheses}

The null hypothesis implies that team work makes no significant difference between the treatment group and the control group in case of their writing proficiency. To test this hypothesis, the two groups were first checked for their pretest scores to see if they were comparable at the onset of the study. The independent samples $t$ test showed no significant difference between the two groups $(\mathrm{t}(62)=-.47, \mathrm{p}=.64)$. Both the treatment group and the control group significantly improved from the beginning to the end of the instruction as assessed through the use of two paired samples t tests (Treatment Group $t(30)=-26.42, p=.000$; Control Group $t(32)=-15.70, p=.000$ ). However, the two groups showed a significant difference in their posttest $(\mathrm{t}(62)=2.64, \mathrm{p}=.01)$.

Our sample is almost normally distributed because the Skewness and Kurtosis statistics obtained do not deviate that much from zero.

Some scholars (e.g. Hatch \& Lazaraton, 1991) believe that in such cases one needs to compare the two groups' gain scores (post test - pretest). This way any differences in the two groups at the onset of study are controlled for. Although the two groups did not differ significantly in the pretest as shown above, the data was analyzed using this approach. It was observed that the treatment group significantly outperformed the control group $(\mathrm{t}(62)=4.56, \mathrm{p}=.000)$.

The effect size (eta squared) was calculated for this comparison. It turned out to be .25 , which according to Cohen (1988) is very large.

\section{DisCUSSION}

The results obtained in chapter four showed that both groups significantly improved over time, which shows that the instruction has been successful for both groups. However, while being almost the same at the pretest, the two groups significantly differed from each other at the end of the instruction. The treatment group outperformed the control group by almost half a band score on TOEFL iBT task 2 writing scoring rubric. This improvement shows that team work can help learners improve their writing ability in English.

However, a more precise examination of the written samples collected from the students in both groups during the semester showed a much wider range of differences between the two groups. By the end of the semester, those in the treatment group appeared to have a better topic development, most probably due to the collaboration they had with their peers and team in brainstorming and outline writing. Having practiced doing so together, the learners seem to have learned how to do brainstorming and outline making even when they have to do them individually in an exam session. They were also observed writing longer paragraphs, which seems to be another consequence of brainstorming and outline preparation together with their peers.

While the writing samples written by the control group were mostly characterized with short sentences and excessive use of 'and' as a connector, the paragraphs written by learners in the treatment group were observed writing longer and complex sentences. Even when they used simple sentences, they could connect them together more logically with the use of a variety of connectors. There were even more cases of the use of subordination in the writing samples of the treatment group than those of the control group. This could be explained by the peer feedback and peer correction they had received during their team work.

In addition, the accuracy in the written samples of the treatment group was much more noticeable, which could be 
due to the team work on the revising and editing of their written paragraphs.

\section{PEDAGOGiCAL IMPLiCATIONS}

Today most of the scholars assert that collaborative writing has the potential to be far superior to individual writing because the weaknesses and inadequacies of individuals are caught by one another, while the strengths of the individuals are pooled. As such, the first implication this study may have applies to language teachers. The results showed that group work is more effective than working individually, at least in case of writing skill. Therefore, teachers teaching writing can use the findings of this study to improve their learners' writing ability. Teachers can ask students to write collaboratively in their classes. This way, students do not merely write down their ideas, but are engaged in discussions and receiving information from their group mates. Moreover, the students can get help and feedback as much as they can help others. As such, learners can view writing from a wider perspective, that is, that of a writer as well as a reader.

Syllabus designers can also benefit from the results of this study. Incorporating group work as part of the instruction can be very helpful to learners participating in any language program. Material developers are the third group who can use the obtained results. Incorporating those findings into the materials they develop can help learners learn much more with their classmates than they can alone.

\section{SUGGESTIONS FOR FURTHER RESEARCH}

The written samples were rated using a holistic scoring rubric which gives a single score as an indicator of the learners' overall writing proficiency. It can be a good idea to do the same story using an analytic scoring rubric such as the one used by IELTS. This way, one can get a profile of scores which help have a better picture of learners' writing ability.

In the present study, students were divided into groups of three. The results might be different if the grouping pattern changes. Pair work might be either more or less helpful, but only further research can tell us which one is the case.

A separate study is also needed to check the effect of peer feedback and correction on different aspects of learners' writing ability. Grammatical accuracy, lexical diversity, and topic development are only some of the aspects needing more attention.

Finally, the same study can be replicated with other proficiency levels. The results may be different if collaborative writing is studied with advanced learners of English.

Note:

Definition of the important terms

Cooperation/collaboration:'(in learning) working together with one or more peers to solve a problem, complete a learning task, share information or get feedback.'

Process approach: (in teaching composition) an approach which emphasizes the composing processes writers make use of in writing (such as planning, drafting and revising).

Holistic Scoring: A method of scoring students' composition in which one or more evaluators read the paper as a whole, assigning a single score based on the total impression of a composition as a whole text or discourse.

\section{REFERENCES}

[1] Brumberger, E.R. (1999). Collaborative projects in a technical writing class: A Cost Benefit Analysis. Teaching English in the two year college, 27(2), 194-203.

[2] Cohen, J. (1988). Statistical power analysis for the behavioral sciences. Hillsdale, NJ: Erlbaum.

[3] Ferris, D. R. (1994). Rhetorical strategies in student persuasive writing: Differences between native and non-native English speakers. Research in the teaching of English, 28(1), 45-65.

[4] Ghaith, G. (2001). Learners' perceptions of their STAD cooperative experience. System 29(1), 289-301. American university of Beirut.

[5] Ghaith, G. and Yaghi, M.H. (1998). Effect of cooperative learning acquisition of second language rules and mechanics. System, 26(2), 223-234. American university of Beirut.

[6] Hatch, E. \&Lazaraton, A. (1991). The research manual. New York: Newbury House.

[7] Jacobs,G. (1998). Cooperative goal structure: A way to improve group activities. ELT Journal, 42(2), 97-101. Oxford University Press.

[8] Johns, M. A. (1998). Written Argumentation for real Audiences: Suggestions for teacher and classroom practice. TESOL Quarterly, 27(1), 75-89. San Diego State University.

[9] Kagan, S. (1992). Cooperative learning. San Juan Capistrano, CA: Kagan Cooperative Learning.

[10] Keyser, W. M. (2000). Active learning and cooperative learning: Understanding the differences and using both styles effectively. Research strategies, 17, 35-44. James C. Jernigan Library, Texas A \& M university- Kingsville; TX, USA.

[11] Kirkland, M. R. and Saunders, M. A. P. (1991). Maximizing student performance in summary writing: Managing cognitive load. TESOL Quarterly, 25(1), 105-121. George Washington University.

[12] Leki, I. (1991). Twenty-five years of contrastive Rhetoric: Text analysis and writing pedagogies. TESOL Quarterly, 25(1), 123-143. University of Tennessee.

[13] Rao, Z. (2007). Training in brainstorming and developing writing skills: ELT Journal volume 61/2: Oxford University press. 
[14] Rollinson, P. (2005). Using Peer feedback in the ESL writing class: ELT journal volume 59/1: Oxford University Press.

[15] Spacks, R. (1998). Initiating ESL students into the academic discourse community: how far should we go? TESOL Quarterly 22/1: 29-51. California state university, Sacramento.

[16] Vygotsky, L. (1986). Thought and Language (Newly revised and edited by A. Kozulin). Research Cambridge, Mass. :MIT Press.

[17] Tan, G., G., Gallo, P. B., Jacobs, GM. and Lee, C. K. (1999).Using cooperative learning to integrate thinking and information technology in a content-based writing lesson. The Internet TESL Journal, 1-14.

[18] Zimmet, N. (2000). Engaging the disaffected: Collaborative Writing across the curriculum projects. English Journal, 90(1), 102-106.

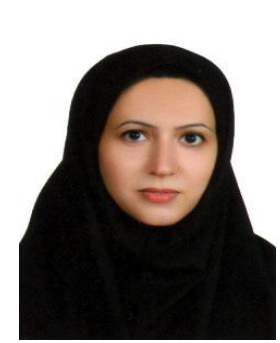

Masoumeh Shiri Aminloo was born in Iran in 1972. She is a Ph.D student in Ferdousi Mashad University studying Applied Linguistics.

She is a faculty member in Damavand Islamic Azad University. General English Grammar (Tehran, Iran: Sanjesh Takmili publication, 2005) is one of her books.

Ms Shiri Aminloo is now in charge of the English Department in Damavand Azad University. 